\title{
Os cientistas ambientais brasileiros cumprem o contrato social metafórico da ciência?
}

A missão dos cientistas pelo Contrato Social Metafórico da Ciência (CSMC) firmado com o governo federal é produzir e difundir informações de modo que a sociedade que os sustenta viva adequadamente. Essa difusão é feita aos seus pares pela disseminação científica e a sociedade leiga pela divulgação científica. $O$ que é disseminado precisa ser traduzido para a sociedade leiga. Foi selecionada a especialidade científica ambiental da ficologia para estudo de caso. Hipotetizou-se que os cientistas-ficólogos brasileiros não vêm realizando a divulgação científica adequadamente para a sociedade leiga. A amostragem objetivou identificar a produtos de divulgação científica (DC) pelos ficólogos no país de janeiro/1999 a outubro/2015. Como os produtos de DC mais conhecidos são artigos de DC foram buscados os que fossem sobre ficologia nas revistas Ciencia Hoje $(\mathrm{CH})$ e Ciencia Hoje das Crianças $(\mathrm{CHC})$ no mesmo período. Foram identificados dezesseis produtos, sendo dez relatados por ficólogos (30\% de artigos escritos; $20 \%$ de Ciclo de Debates; $20 \%$ de Oficinas de Simulação da vida laboratorial; $10 \%$ de vídeos científicos; $10 \%$ de livros; $10 \%$ de comentários em blog internacional) e seis artigos escritos na $\mathrm{CH} / \mathrm{CHC}$. A produção de $\mathrm{DC}$ por produtos escritos de artigos de ficólogos representaram 0,004\% na revista $\mathrm{CH}$ e 0,0056\% na CHC. Então, 1,6\% foram os produtos que cientistas-ficólogos contribuíram em quinze anos sobre DC relativo a algas em um universo de 1.000 ficólogos, sugerindo uma contribuição incipiente. A hipótese pode ser comprovada. Os cientistas ambientais (representados pelos ficólogos) só cumprem parcialmente o CSMC, não comunicando-se com a sociedade pela divulgação científica.

Palavras-chave: Divulgação-Científica; Popularização da Ciência; Contrato Social; Ficologia; Ambiente.

\section{Do brazilian environmental scientists fulfill science's social contract?}

The mission of the scientists for the Metaphorical Social Contract of Science (CSMC) is to disseminate information so that the society that supports them properly subsist. Through the scientific popularization, the science that is disseminated by scientists translates itself to a secular society. We selected as a case study the scientific specialty called phycology. We formulated the hypothesis that Brazilian phycologists disseminate appropriate information to their peers, but do not adequately spread it to the secular society. The sampling aimed to identify science communication products (DC) by phycologists in the country, from January/1999 to October/2015, and raise DC papers in phycology at journals Ciência Hoje and Ciência Hoje das Crianças. We identified sixteen products, ten targeted to phycologists ( $30 \%$ of written papers, $20 \%$ of debates, $20 \%$ of simulation workshops of laboratory life, $10 \%$ of scientific videos; $10 \%$ of books; $10 \%$ of comments on international blog). Then $0.016 \%$ were products of phycologists that contribute in DC on algae, in a universe of 1,000 phycologists, suggesting an incipient contribution. The DC production by articles from phycologists in Ciência Hoje magazine was of $0.004 \%$ and Ciência Hoje das Crianças was $0.0056 \%$. The conclusion is that the hypothesis can be proven. Brazilian phycologists do not adequately communicate with society. Production in science popularization is incipient and phycologists only partially meet the CSMC.

Keywords: Scientific Divulgation; Popularization of Science; Social Contract; Phycology; Environment

Topic: Ensino Superior, Pesquisa e Extensão

Reviewed anonymously in the process of blind peer.

\section{Alexandre de Gusmao Pedrini}

Universidade do Estado do Rio de Janeiro, Brasil

http://lattes.cnpq.br/6918956483557789

pedrini@globo.com

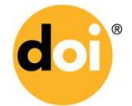

DOI: $10.6008 / S P C 2179-6858.2016 .002 .0013$
Received: 05/01/2016

Approved: 10/04/2016

\section{Referencing this:}

PEDRINI, A. G.. Os cientistas ambientais brasileiros cumprem o contrato social metafórico da ciência?. Revista lbero-Americana de Ciências Ambientais, v.7, n.2, p.156-173, 2016. DOI: http://doi.org/10.6008/SPC2179-6858.2016.002.0013 


\section{INTRODUÇÃO}

A população brasileira requer variadas demandas para se desenvolver. A inclusão social é uma das mais árduas. Ivanissevich (2009) aponta a popularização ou divulgação da ciência como uma das mais hercúleas e difíceis, pois ela deve alcançar todas as faixas etárias e camadas sociais do país. A capacitação informacional da população em Ciência e Tecnologia permitirá que ela se incorpore de criticismo para tomar decisões quanto ao que o país deve ou não desenvolver como política no campo. A autora entende essa missão como de responsabilidade tanto do jornalista científico como do cientista. O pesquisador que produz ciência vem apresentando-a como de inegável contribuição à sociedade. A ciência e tecnologia estão presentes no cotidiano tanto urbano como rural e tanto nos equipamentos que usamos como em nossos alimentos e remédios. A ciência, em especial, responsável pela obtenção de dados (medida em um determinado contexto), informação (dado que modifica o contexto a que se destina) ou conhecimento/saber (informação que transforma a realidade para a qual foi produzida) vem possibilitando a melhoria da qualidade de vida da humanidade (BARRETO, 1994). Como, por exemplo: a descoberta de novos fármacos, alimentos saudáveis, utensílios domésticos, equipamentos livres de poluição, etc. (ZIMAN, 1979).

Essa melhoria do bem-estar e da qualidade de vida da humanidade tem sido uma meta permanente dos cientistas desde os primórdios da história humana. Porém, infelizmente, uma ínfima parte dos cientistas se colocou a serviço da tirania e do crime. Na era clássica ajudaram a construir navios mais destruidores a serviço da guerra (THUILIER, 1989). Ou pior ainda ajudaram a exterminar milhões de judeus, ciganos e doentes mentais (MULLER-HILL, 1993) por determinação de nazistas. Porém, com a Segunda Guerra Mundial vencida pelos aliados, em grande parte, devida pela contribuição fundamental de cientistas-físicos um acordo tácito foi construído. Trata-se do Contrato Social Metafórico da Ciência (CSMC) firmado entre cientistas e o Governo Federal (GF), representando a sociedade. Caberia aos cientistas agirem honestamente e disponibilizar a sociedade fármacos, alimentos e armas (dentre outros produtos) e o GF financiaria todas as pesquisas solicitadas pela comunidade científica (GUSTON et al., 1994). No entanto, essa época dourada em que o GF financiaria tudo que os cientistas solicitassem nunca ocorreu e ocorreram casos de má conduta de cientistas que também nem sempre disponibilizaram os produtos negociados. Porém, esse acordo mesmo fragilizado sempre é alardeado nas justificativas dos projetos de pesquisa que pleiteiam verbas, tanto aos órgãos governamentais de fomento científico quanto as entidades privadas de origem variada.

Há tipologias variadas quanto à classificação de como a comunicação científica é realizada, segundo o público a que é dirigida. Massarani et al. (2005) apontam como sendo três as formas: a) discursos científicos primários (cientistas para cientistas); b) discursos didáticos (cientistas para alunos); c) divulgação científica (cientistas para a sociedade). Segundo Bueno (1985) a produção de dados, informações e saberes e sua comunicação como um todo é definida como sendo Difusão Científica (Quadro 1). Quando ela tem como objetivo os pares dos cientistas ela é denominada de Disseminação Científica. E quando tal disseminação é dirigida para o público leigo ela chama-se Divulgação/Popularização Científica (DC). 
Quadro 1: Classificação da comunicação científica, segundo o produtor e o receptor (Adaptado de BUENO, 1985).

\begin{tabular}{|l|l|l|l|}
\hline \multicolumn{1}{|l|}{} & $\begin{array}{l}\text { Disseminação Científica } \\
\text { (Incluindo livros didáticos ou } \\
\text { paradidáticos) }\end{array}$ & Produtor & Receptor \\
\cline { 2 - 4 } $\begin{array}{l}\text { Difusão } \\
\text { Científica }\end{array}$ & $\begin{array}{l}\text { Divulgação/Popularização } \\
\text { Científica }\end{array}$ & $\begin{array}{l}\text { Cientista/Jornalista especializado } \\
\text { da entidade do cientista }\end{array}$ & $\begin{array}{l}\text { Público “leigo ou cientista de } \\
\text { especialidade diferente do } \\
\text { produtor }\end{array}$ \\
\cline { 2 - 4 } & $\begin{array}{l}\text { Jornalismo Científico/Comunicação } \\
\text { pública em ciência e tecnologia }\end{array}$ & $\begin{array}{l}\text { Jornalista/escritor especializado diferente do } \\
\text { em C \& T da/para a mídia }\end{array}$ & Público "leigo" \\
\hline
\end{tabular}

A DC também pode ser compreendida pelo campo da comunicação pública em Ciência e Tecnologia (C\&T), segundo Fahy et al. (2014), porém numa área mais afeita aos jornalistas. Um manual singelo sobre DC para o público brasileiro é a obra traduzida da canadense Sophie Malavoy (2005). Ele foi produzido para o planejamento da II Semana Nacional de Ciência e Tecnologia e recebeu o apoio do Ministério de C\&T do Brasil e da Fundação Oswaldo Cruz. Quando o jornalista deseja comunicar ao grande público notícias sobre a ciência chama-se a essa atividade de Jornalismo Científico. Esse tema não será adotado nesse artigo, mas possui várias publicações emblemáticas editadas no Brasil (BURKETT, 1990; NELSON, 1994; OLIVEIRA, 2005; FAUSTO NETO, 2012) que discutem como desenvolvê-las. lannini et al. (2007) designam que a DC pode ser organizada em: a) Educação e Comunicação em Museus; b) Jornalismo Científico; c) Comunicação Pública da Ciência; d) Ensino de Ciências. Então o escopo da DC tem sua delimitação em expansão.

A disseminação da informação nas variadas especialidades científicas é considerada como mais importante quando feita por periódico a despeito de anais de eventos. A ida a eventos hoje em dia (varia segundo a especialidade científica) é vista principalmente como forma de apresentar o que foi descoberto de mais recente e fora das seções de apresentações de trabalhos articular cooperações de pesquisa. Muitas vezes trabalhos apresentados em eventos são depois reapresentados a periódicos e por eles publicados. Esse produto é então considerado final e não pode mais ser republicado. Ele poderia ser republicado com outra linguagem como a que seria traduzida para o público leigo, transformando-se num produto de divulgação científica. Um jornalista poderia ainda republicar os dados do primeiro artigo em um jornal escrito ou virtual, sendo assim um texto de jornalismo científico. $O$ tema do presente artigo é sobre algas.

A especialidade da ciência que estuda as algas chama-se ficologia ou algologia. Algas segundo Oliveira Filho (2003) e Horta et al. (2010) podem ser conceituados didaticamente como um agrupamento artificial de organismos que filogeneticamente são díspares (chegando a se constituir em reinos diferentes), mas predominantemente aquáticos fotossintéticos avasculares cuja estrutura de reprodução é destituída de uma camada de células estéreis isolando-a. No Brasil, a disseminação de artigos vem sendo feita (a partir da década de noventa do século passado) por variados periódicos respeitados pelos botânicos e ficólogos (por exemplo: Acta Botanica Brasilica, Brazilian Journal of Oceanography, Hoehnea, Iheringia-Botânica, Revista Brasileira de Botânica, Rodriguesia, etc). No exterior, os periódicos onde os cientistas brasileiros vêm publicando são considerados como de grande impacto positivo na ciência (Botanica Marina, Phycologia, European Journal of Phycology, Journal of Phycology, Journal of Applied Phycology, etc). Porém, não se sabe 
qual a contribuição dos ficólogos na sua comunicação direta com a sociedade. Essa preocupação se insere no campo da Divulgação Científica (DC).

Inexistem periódicos acadêmicos dedicados exclusivamente para divulgação científica da matéria ficológica tanto no Brasil como no exterior. Mas, há vários periódicos internacionais de divulgação científica que abrangem temas ficológicos, como exemplos Scientific American e New Scientist. Um dos sites, em língua inglesa, de divulgação científica mais comuns é o "Science Daily". Ele tem como fonte corrente o Georgia Institute of Technology (GIT) que busca informações científicas sobre assuntos variados como algas diretamente de artigos de periódicos de disseminação científica (GIT, 2015). Em relação a livros estrangeiros com a intenção de serem dirigidos ao público leigo há a uma obra emblemática notável: a de Braune e Guiry (2001). É um detalhado manual, abrangendo 401 gêneros e centenas de espécies, sendo 29 gêneros de algas verdes, 105 de algas pardas e 267 de algas vermelhas. Incluí metodologias de como coletar, acondicionar e construir um herbário ficológico em moldes científicos, além de um glossário de termos técnicos. Em língua portuguesa há a obra de Vieira et al. (2013) que trata especificamente da biota bentônica das praias rochosas da costa norte de Portugal. Compõe-se de 54 organismos, sendo 30 táxons de macroalgas, 3 de líquens e 21 de animais, além de um glossário básico e noções de ecologia costeira. Porém, como dito acima a DC não se resume a publicações em papel. Com a expansão do ambiente virtual vários instrumentos estão sendo apresentados, e, muitas vezes superam as delimitações físicas de um país. Esse tema demandaria outro artigo.

\section{REVISÃO TEÓRICA}

\section{A Divulgação Científica no Brasil}

A Divulgação Científica (DC) vem sendo denominada sob variados entendimentos no Brasil. Um deles, o de Zamboni (2001) conceitua a DC como aquele processo em que o discurso científico é reformulado para outro adaptado ao público em geral. Acrescentaria que o discurso científico seria traduzido para um determinado público com características próprias. Porém, essa tradução carece de cuidados ideológicos, dentre outros, pois, ela pode auxiliar a reproduzir injustiças causadas por modelos econômicos excludentes socialmente que impõem desajustes ambientais variados a comunidade retratada. A DC está intimamente relacionada a percepção pública da C \& T. Essa percepção pode ser um dos reflexos da efetividade da DC.

A percepção popular brasileira quanto ao campo da Ciência e Tecnologia mesmo no passado, segundo o Ministério de Ciência e Tecnologia (MCT, 1988) já demandava maior aporte financeiro do GF. Na época para cerca de $65 \%$ dos brasileiros o governo federal não financiava com recursos adequados os cientistas e inventores brasileiros. E para cerca de 70\%, a pesquisa científica era útil ao país e devia-se investir mais na área, pois cerca de $50 \%$ dos brasileiros achavam que o país era mais atrasado que outros em termos científicos e tecnológicos. E a maioria dos entrevistados achava que deveria haver mídias que informassem o grande público sobre o avanço científico e tecnológico no Brasil. Isso seria a criação de programas de DC. Recentemente, Laplane et al. (2015) atualizaram esse estudo e verificaram que houve mudanças. $\mathrm{O}$ acesso a 
informação em ciência passou a ser mais pela Internet do que pela TV. E o interesse por informação da ciência ambiental aumentou. Cresceu também a visitação a espaços e eventos em C \& T, embora apenas para jovens. A camada mais humilde continua sem esse acesso. A ciência como geradora de benefícios aumentou na percepção popular e apenas uma minoria (4\%) ainda crê que traga mais malefícios que benefícios. $O$ Índice de Confiança de Cientistas de universidades ou entidades públicas de pesquisa continua sendo o mais alto entre todas os sujeitos pesquisados. Então, pode-se, brevemente, concluir, que a percepção pública em ciência no Brasil é adequada, apesar de ainda precisar ser melhorada em termos de espaços e eventos para debate de agenda participativa de pesquisa. A DC deve então propugnar em seus produtos uma centralidade um convite a sociedade para a construção da agenda de pesquisa do que de fato interessa a sociedade brasileira. Nesse caso, precisam ser criados editais que financiem a construção de estratégias metodológicas de $\mathrm{DC}$ em que o cientista convide a sociedade a dialogar in loco nos seus laboratórios. E, mesmo a conviver no seu cotidiano laboratorial e compreender o empreendimento científico.

A DC se iniciou como área de pesquisa, no Brasil, na década de cinquenta com os escritos do cientista José Reis (REIS, 1954). Desde então, cientistas de vários quilates e especialidades empreenderam esforços para tornar a DC uma preocupação de estado no Ministério de C, T e I. Moreira (2006) empreendeu sérios e intensos esforços nesse Ministério para a criação do Departamento de Difusão e Popularização de Ciência e Tecnologia (DPCT). Segundo Moreira (2006) o DPCT tinha dezenas de metas a atingir. Esse departamento aplicou, no Brasil, investimentos da ordem de $\mathrm{R} \$ 140.000 .000,00$ de 2003-2014 (MCTI, 2015). Cerca de 30\% foram em feiras e mostras científicas, $23 \%$ em expansões físicas de museus de ciência, $8 \%$ nas Semana Nacional de C \& T e 16\% para Olimpíadas Científicas. Muito de perceptível pode ser visto em DC no país. Porém, não foi feita ainda uma metavaliação que possa indicar o seu grau de eficácia na comunicação de temas científicos entre cientistas e cidadãos (MASSARANI et al., 2002). Kidd (1988) estimou que se produzia internacionalmente cerca de 2000 produtos de DC para cerca de 400.000 artigos/ano publicados. Então a popularização ou divulgação científica representava cerca de $0,5 \%$ do que se publicava na década de oitenta do século passado. Infelizmente inexistem esses dados no Brasil.

Independente dos esforços do governo federal os estados mais ricos da federação criaram editais de fomento a DC. Serão exemplificados nos estados do Rio de Janeiro e São Paulo. A Fundação Carlos Chagas Filho de Amparo à Pesquisa do Estado do Rio de Janeiro (FAPERJ) criou um programa intitulado "Apoio à difusão e popularização da Ciência e Tecnologia no Estado do Rio de Janeiro" (FAPERJ, 2013). A primeira edição foi em 6 de junho de 2007 com o fim de estimular a que os cientistas mostrassem a população fluminense o que viam produzindo em dados e informação científica. Um balanço nesse programa de 20072012 mostrou que dos cerca de 600 projetos submetidos aproximadamente 250 foram aprovados, investindo-se cerca de $\mathrm{R} \$ 10.000 .000,00$. Os valores médios das verbas concedidas foram de $\mathrm{R} \$ 24.000,00$ (2007) - R\$47.000,00 (2012). No entanto, as especialidades incluídas nas Ciências Biológicas, como a ficologia foram as que menos tiveram pleitos aprovados; apenas $19 \%$ de projetos aprovados contra cerca de $26 \%$ nas Ciências Humanas. A Fundação de Amparo à Pesquisa do Estado de São Paulo (FAPESP) tem sido considerada atualmente a entidade estadual da federação de maior confiabilidade atual na concessão de verbas públicas 
para pesquisa acadêmica. A FAPESP (2014) possui um programa especial intitulado "Jornalismo Científico (=Mídiaciência)" também denominado de Programa José Reis de Incentivo ao Jornalismo Científico. Seu objetivo principal é apoiar a formação de profissionais que promovam a divulgação científica pela concessão de bolsas de graduação e pós-graduação. O produto desejado é texto para publicação em veículos de comunicação de qualquer natureza. No entanto, o volume de recursos aplicados tem sido restrito de 20092014 no valor de cerca de $\mathrm{R} \$ \mathbf{7 2 5 . 0 0 0 , 0 0}$ apenas para universidades estaduais públicas. Mas, há investimentos para a popularização da C\&T dispersos em outras rubricas da fundação que não foram arroladas nesse artigo. Independente da constância de verbas públicas para investimento na popularização da C \& T alguns pesquisadores vêm se dedicando a esse tema como cerne de suas preocupações. Um exemplo dessas equipes de pesquisas é o Programa de Pós-Graduação em Educação para a Ciência da Unesp (Campus Bauru), estado de São Paulo. Segundo Perez et al. (2006) a DC exercita o dever considerado ético por esses dois autores da prestação de contas dos cientistas a sociedade. Em alguns projetos de pesquisas há investimento muito alto de recursos financeiros que nem sempre resultam em informação útil a sociedade. Tendo como fim a DC, os pesquisadores da Unesp Araújo et al. (2006) consideram que a Alfabetização Científica (AC) seria o processo, pelo qual, a DC seria alcançada. Há outras perspectivas de informar cientificamente a sociedade e de medir sua incorporação como o Índice de Letramento Científico (ILC). O Instituto Abramundo et al. (2014) criou o ILC com o fim de monitorar a evolução das habilidades de letramento científico da população brasileira para qualifica-la no debate sobre políticas públicas. O letramento e o alfabetismo se imbricam, porém sua classificação parece mais detalhada. Essa pesquisa arrolou cerca de 2.000 pessoas pelo país em 92 municípios, representando 23 milhões de brasileiros. Das principais conclusões cerca da metade da população mostrou ter letramento científico rudimentar, mas incapaz de interpretar informações de natureza científica.

A Alfabetização Científica AC está ocorrendo em três níveis em função dos seus variados processos na sociedade, podendo ser classificados nos seguintes estágios: a) no primeiro estágio o cidadão percebe a ciência como individual, realizada apenas por gênios: o que ela realiza não pode ser questionado e sua produção de descobertas é idealizada e complexa; b) no segundo estágio a ciência é representada como uma construção humana coletiva e não uma verdade absoluta; c) no terceiro estágio é aquele em que a ciência é realizada por uma comunidade científica internacional. Para que a sociedade possa incorporar informações que possam ser transformadas em conhecimentos científicos no seu cotidiano, necessitando estar situada, no mínimo, no segundo estágio.

Assim, é necessário que haja uma Educação Científica do cidadão. E há que se aproveitar todas as possibilidades de aprendizagens. Araújo et al. (op. cit.) argumentam que o aprendizado sobre a AC pode ocorrer basicamente de quatro modos: a) ao acaso, que pode ocorrer a qualquer momento, numa conversa, por exemplo; b) informal, em que ela é intencional, mas desestruturada, podendo ser obtida pela leitura de jornais; c) formal, em escolas ou universidades, através de disciplinas organizadas em um currículo; d) não formal, aquela realizada fora das disciplinas, podendo inclusive ocorrer em conversas nos intervalos das aulas 
curriculares. Por essa perspectiva, não formal, existem dezenas de possibilidades da AC ocorrer, como, podem ser visualizadas, grande parte delas, no Quadro 2.

Quadro 2: Esforço de síntese para classificação de métodos possíveis de divulgação científica, segundo o pressuposto do perfil da sociedade quanto ao nível de informação dela sobre ciência e suas respectivas estratégias metodológicas para informar a sociedade.

\begin{tabular}{|c|c|c|}
\hline Pressuposto & Direção & \begin{tabular}{|l} 
Estratégias Metodológicas \\
\end{tabular} \\
\hline \multirow{9}{*}{$\begin{array}{l}\text { Sociedade desinformada } \\
\text { no tema }\end{array}$} & \multirow{7}{*}{$\begin{array}{l}\text { Unidirecional } \\
\text { (Emissor ativo/Receptor } \\
\text { passivo) }\end{array}$} & $\begin{array}{l}\text { Textos físicos (livros, artigos em papel ou virtuais, revista de } \\
\text { banca de jornal, cordel, jornal, etc) }\end{array}$ \\
\hline & & Audições de rádio \\
\hline & & Projeções de filmes/vídeos \\
\hline & & Museus expositivos fixos ou itinerantes \\
\hline & & Hipertextos; blogs \\
\hline & & Exposições, feiras, festivais \\
\hline & & Entrevistas a mídia \\
\hline & \multirow{2}{*}{$\begin{array}{l}\text { Bidirecional/Dialógica } \\
\text { (Emissor/Receptor ativos) }\end{array}$} & Rede social \\
\hline & & Ciclo de debates \\
\hline \multirow{8}{*}{$\begin{array}{l}\text { Sociedade basicamente } \\
\text { informada }\end{array}$} & \multirow{6}{*}{$\begin{array}{l}\text { Multidirecional/Dialógica/Vive } \\
\text { ncial (Emissor/Receptor ativos) }\end{array}$} & Roda de conversa \\
\hline & & Café científico \\
\hline & & Museus interativos (p. ex. Casa da Ciência; Museu da Vida) \\
\hline & & Jogos \\
\hline & & $\begin{array}{l}\text { Brincadeiras, contação de histórias, paródias, canto de música, } \\
\text { tribunal, teatralização, etc }\end{array}$ \\
\hline & & Dinâmicas \\
\hline & \multirow{2}{*}{$\begin{array}{l}\text { Multidirecional/Dialógica/Simu } \\
\text { lada ou Real (Emissor/Receptor } \\
\text { ativos) }\end{array}$} & Simulação da vida laboratorial \\
\hline & & $\begin{array}{l}\text { Conviver com o cotidiano do cientista e com ele dialogar na } \\
\text { produção de informação }\end{array}$ \\
\hline
\end{tabular}

Obras restritas de DC envolvendo algas que foram traduzidas a língua portuguesa a mais interessante é a de Carson (2010). A bióloga Rachel Carson está imortalizada pela sua obra Primavera Silenciosa que marcou o início da luta internacional ambientalista. Ela escreveu inúmeros livros como o "Beira Mar" publicado em 1955 nos EUA. Nessa obra, apresentou inúmeras espécies de macroalgas como Ascophyllum nodosum, Chondrus crispus, Fucus spiralis, Laminaria digitata, Palmaria palmata e Pelvetia canaliculata. Aqui as algas foram sempre citadas se relacionando com outras espécies de organismos ou interagindo com as forças da natureza de uma maneira simples, convincente e instigante.

No Brasil, a única obra de DC envolvendo organismos marinhos é a de Rosa (1964), abordando os animais comuns nas praias do sudeste brasileiro. Fora isso, há apenas os livros de Nassar (2012), Soriano et al. (2009) e os de Pedrini (2010b, 2010c, 2011, 2013) da série flora marinha do Brasil. Porém, eles são dirigidos a jovens iniciantes da carreira científica e que seriam, de fato, obras didáticas de disseminação científica. Há outras obras dirigidas à EA, como a de Ghilardi-Lopes et al. (2012) e Pedrini (2010a) que também colaboram com a DC, mas que não tiveram esse objetivo. Pesquisas sobre a percepção do ambiente marinho e seus constituintes biológicos também estão sendo feitos. Na maioria destas pesquisas as algas têm sido confundidas com animais como corais (OIGMAN-PSZCZOL et al., 2007). E também em pesquisas com o público infantil percebidas como espécies biológicas marinhas importantes só sendo superadas pelos peixes na cidade costeira do Rio de Janeiro (RUA et al., 2015). Esse fato enseja estudo mais aprofundado para entender essa representação social infantil, já que, em geral, no imaginário infantil predominam peixes como tubarão e outros seres marinhos (VASCONCELLOS et al., 2008). 
As algas, tanto as marinhas como as de água doce têm enorme importância natural como humana. No Brasil, sua importância ecossistêmica a cada dia vem sendo consolidada em variadas situações e aplicações (PEDRINI, 2010c). Quanto à introdução de espécies se pesquisa muito e se discute sobre a rodófita Kappaphycus alvarezii (Doty) Doty ex P. C. Silva (CASTELAR et al., 2009), pois ela produz uma excelente carragenana (coloide de aplicação industrial). Porém, o povo brasileiro não consome as algas como alimento cotidiano como nos países orientais. Talvez por isso ela não seja tão conhecida pela população. As algas, segundo Pedrini (2010b) têm dezenas de contribuições fundamentais para a sobrevivência do planeta Terra como, por exemplo: a) ser fonte essencial de alimento aos organismos herbívoros; b) ser produtora de oxigênio na fotossíntese, e, cujo excedente em sua respiração permite que os organismos heterotróficos como o Homem possam respirar; c) sequestrar o carbono excedente na natureza devido a contribuição antrópica.

Desse modo, urge que seja conhecido o que os ficólogos possam ter formulado como produtos de DC para o público brasileiro, cumprindo assim a parte que Ihes cabe no Contrato Social Metafórico da Ciência. Vale conhecer desde ações unidirecionais passivas até produtos que levem o cidadão a conhecer a simulação da vida cotidiana de um cientista (PEDRINI et al., 1999). Ou a conviver na vida laboratorial cotidiana do cientista como nos trabalhos de Knorr-Cetina (1981) e Latour e Woolgar (1997). A hipótese apresentada, então, é a de que os ficólogos realizam a disseminação de dados e informação aos seus pares, porém não adequadamente a divulgação científica aos cientistas não pares e ao público leigo da sociedade brasileira.

\section{METODOLOGIA}

Em face do limitado conhecimento do tema DC em ficologia, tentou-se recuperar trabalhos brasileiros e estrangeiros nas línguas portuguesa, espanhola, inglesa e francesa sobre o tema nas seguintes fontes: a) Google; b) www.seaweed.ie; c) www.periodicos.capes.gov.br (Portal Brasileiro de Periódicos da CAPES); d) scholar.google.com.br (Google Scholar); d) ResearchGate.net; e) Academia.edu. Foram utilizadas as seguintes palavras-chaves em português/inglês: vulgarização do conhecimento científico, divulgação científica, popularização científica, difusão científica, jornalismo científico, percepção ou comunicação pública em C\&T.

Com a finalidade de obter todos os produtos possíveis dos cientistas especialistas em algas (ficólogos) foi enviado um questionário, contendo um quadro com os produtos mais comuns de DC listados. Esses produtos estão listados como estratégias metodológicas no Quadro 2. Caberiam aos cientistas preenchê-lo e agregar outras possibilidades também. Esse instrumento de coleta de dados foi enviado aos cerca de 1.000 membros da Sociedade Brasileira de Ficologia (SBFic), em setembro e outubro de 2015. Além disso, o questionário foi colocado no grupo de ficólogos do numa rede social, convidando-os ao preenchimento. Como o produto de DC mais conhecido entre os cientistas brasileiros é o texto escrito, foi feita uma pesquisa nos dois periódicos genuinamente brasileiros de DC. Eles pertencem à Sociedade Brasileira para o Progresso da Ciência (SBPC). São eles a Ciência-Hoje e a Ciência-Hoje das Crianças. Tanto a pesquisa pelo questionário como pela palavra-chave (algas) o período coberto pela investigação foi de janeiro de 1999-outubro de 2015. 
Esses dados foram obtidos pelas editoras, pois quando solicitados pelo mecanismo de busca do site são oferecidas respostas confusas e muito misturadas com outros temas. Para determinar o número médio total de artigos publicados de variadas disciplinas por ano em $\mathrm{CH}$ e $\mathrm{CHC}$ foi adotado o valor estimado médio de 45 sugerido por sua editora. Assim esse valor foi multiplicado pelo número de anos cobertos pela presente pesquisa. Para 2015 o valor foi proporcional ao número de meses incluídos. Então a memória de cálculo seria 45 matérias x 15 anos +9 meses de matérias=34=709. Como pressuposto teórico ideal mínimo de produto de DC por cientista, considerando o CSMC foi considerado o de um item.

\section{RESULTADOS}

\section{Produtos Totais}

Os resultados quanto aos produtos obtidos pelo questionário estão apresentados no quadro 3.

Quadro 3: Resultados preliminares obtidos sobre produtos relatados sobre divulgação científica, abordando algas de 1995 a out./2015 obtidos diretamente aos 1.000 ficólogos por questionário e classificados pelo veículo de comunicação científica e autores que o produziram.

\begin{tabular}{|c|c|c|c|}
\hline Pressuposto & Produto de DC & Veículo de Comunicação Científica & Autor (es) \\
\hline \multirow{6}{*}{ Unidirecional } & $\begin{array}{l}\text { 1.Artigo de divulgação: } \\
\text { Florestas Submarinas. }\end{array}$ & Revista Ciência Hoje- Crianças. & $\begin{array}{l}\text { Araujo e Széchy } \\
\text { (2015) }\end{array}$ \\
\hline & 2.Vídeo: Maré Vermelha & UFPr TV- Programa Stientia & UFPr, 19.09.2015 \\
\hline & $\begin{array}{l}\text { 3. Texto do Guia para } \\
\text { Educação Ambiental em } \\
\text { Costões Rochosos }\end{array}$ & Livro & Ghilardi et al. (2012) \\
\hline & $\begin{array}{l}\text { 4. Comentário num Blog } \\
\text { de periódico: "Add } \\
\text { coastal vegetation to the } \\
\text { climate critical list" }\end{array}$ & Revista Nature (Nature News) & Copertino (2011) \\
\hline & $\begin{array}{l}\text { 5. Artigo de divulgação: } \\
\text { Biodiversidade em risco. }\end{array}$ & Revista Ciência hoje & Soriano et al. (2008) \\
\hline & $\begin{array}{l}\text { 6. Artigo de divulgação: } \\
\text { Recifes de corais ou } \\
\text { recifes de algas? }\end{array}$ & Revista Ciência hoje & Figueiredo (2000) \\
\hline Bidirecional & $\begin{array}{l}\text { 7/8. I e II Ciclos de } \\
\text { Debates sobre } \\
\text { Conhecimento } \\
\text { acumulado sobre a } \\
\text { Baixada de Jacarepaguá } \\
\text { para moradores da } \\
\text { região. }\end{array}$ & $\begin{array}{l}\text { Anais da VI Reunião da Rede de } \\
\text { Popularização da Ciência e Tecnologia da } \\
\text { América Latina e Caribe. }\end{array}$ & Pedrini (1999) \\
\hline $\begin{array}{l}\text { Multidirecional/Sim } \\
\text { ulado }\end{array}$ & $\begin{array}{l}\text { 9/10. Duas oficinas de } \\
\text { participação pública na } \\
\text { simulação da vida } \\
\text { laboratorial do cientista } \\
\text { no UERJ SEM MUROS. }\end{array}$ & $\begin{array}{l}\text { Anais da VI Reunião da Rede de } \\
\text { Popularização da Ciência e Tecnologia da } \\
\text { América Latina e Caribe. }\end{array}$ & Pedrini et al. (1999) \\
\hline $\begin{array}{l}\text { Multiderecional/Re } \\
\text { al }\end{array}$ & $\begin{array}{l}\text { Vivências no cotidiano do } \\
\text { cientista dialogando com } \\
\text { ele (Etnografia). }\end{array}$ & Não encontrado & Não encontrado \\
\hline
\end{tabular}

O Quadro 3 mostras claramente o desinteresse dos ficólogos em desenvolver atividades de divulgação científica, ou, pelo menos, de documentá-las por escrito e disponibilizá-las publicamente. As reduzidas contribuições (1\%) desenvolvidas (dez) em cerca de 15 anos com maioria absoluta em atividades unidirecionais (60\%) reforçam essa ideia. Ela permite supor também que os ficólogos preferem se comunicar por escrito tentando fazer a decodificação do texto científico hermético para o texto compreensível. Optam 
por formular produtos unidirecionais em que o receptor que é a sociedade se limita a uma postura passiva de leitura sem poder dialogar sobre as descobertas científicas e sobre o que deve ser prioritário a ser pesquisado (FIGUEIREDO, 2000; SORIANO-MARINHO et al., 2009; COPERTINO, 2011).

Os únicos produtos em que a sociedade foi chamada a dialogar atenderam a duas perspectivas. A primeira de interesse imediato à sociedade em que ela foi convidada a conhecer o saber produzido por cientistas. Esse conhecimento era sobre o ambiente em que ela habitava e foi comunicado de modo problematizado através de dois ciclos de palestras informais. Foram realizados então dois eventos de divulgação científica, segundo Pedrini et al. (1999a) cadastrados como produtos de extensão pela Universidade do Estado do Rio de Janeiro. O primeiro foi realizado na UERJ em 1984 e o segundo no Marina Barra Clube no início da Baixada de Jacarepaguá (Pedrini et al., 1984, 1991). Foram arrolados nos dois eventos desde antropólogos e biólogos até gestores municipais que apresentaram ao público a situação socioambiental da Baixada de Jacarepaguá.

A segunda perspectiva, possibilitou mais benefício aos cientistas, pois foi feita uma simulação do seu cotidiano numa outra sala próxima ao laboratório de pesquisa. Este trabalho, seguiu o pressuposto de que a sociedade percebia os cientistas como gênios enclausurados em seus laboratórios, vivendo com condições maravilhosas de trabalho. Buscou-se desmistificar isso. E também mostrar as dificuldades e penúrias passadas por um cientista numa universidade pública estadual. Então apresentou-se a construção social do saber num espaço público universitário. A atividade intitulou-se "Para que servem as algas?" e foi oferecida, duas vezes (em 1993 e 1994) ao público que visitou a UERJ durante o evento "UERJ SEM MUROS" -a maior manifestação entre ciência e sociedade da universidade pública contemporânea brasileira.

Constituiu-se a atividade dos seguintes momentos: a) resposta ao Pré-Teste; b) distribuição de informativo; c) apresentação de audiovisual, descrevendo o cotidiano de um cientista de país periférico; d) realização sequencial das seguintes oficinas instrucionais: 1. Amostragem; 2. Identificação taxonômica; 3. Herborização; 4. Produtos de pesquisa; 5. Produtos comerciais/industriais; e) Pós -Teste; f) Avaliação da atividade; g) Doação de "kit" com produtos de uma farmácia homeopática de manipulação de amostras científicas de algas marinhas. Trinta cidadãos participaram, sendo $53 \%$ de estudantes, $44 \%$ de professores e $4 \%$ mães de alunos presentes. A maioria foi do sexo feminino (74\%). A idade dos estudantes oscilou de 9-20 anos e dos professores 24-51 anos. Responderam à avaliação 25 pessoas. Os participantes eram de 21 escolas, sendo $67 \%$ públicas e destas $47 \%$ de escolas municipais. A maioria absoluta dos alunos classificou a atividade como ótima (maior conceito). Em 1995 foi feita uma avaliação de médio prazo (Pedrini, Comunicação Pessoal), por entrevistas e todos os alunos encontrados reafirmaram sua avaliação anterior. Alguns reutilizaram as amostras doadas em feiras de ciências (alunos) e na sua prática escolar (docentes).

\section{Produtos Escritos}

Foram estudadas as duas revistas brasileiras de maior projeção em divulgação científica no Brasil: a Ciência Hoje $(\mathrm{CH})$ e a Ciência Hoje das Crianças $(\mathrm{CHC})$. Os produtos obtidos junto a esses dois periódicos encontram-se nos Quadros 4 e 5. A produção total de DC medida por artigos escritos em ficologia 
representaram 0,004\% do total da revista $\mathrm{CH}$ e $0,0056 \%$ na $\mathrm{CHC}$. A produção de $\mathrm{DC}$ no tema de ficologia escrita por ficólogos foi de $38 \%$ do total dos trabalhos sobre algas no período na Revista $\mathrm{CH}$ e de $75 \%$ em CHC. Ou seja, a produção em DC tanto no seu conjunto se comparada ao total de cientistas como ao total de matérias na revista de DC consagrada no meio científico parece insignificante. O presente artigo evidenciou que das matérias produzidas em ficologia na $\mathrm{CH}$ a maioria (62\%) foi por jornalistas científicos da própria revista.

O Quadro 4 apresenta oito produtos de DC sob a forma de artigos no periódico Ciência Hoje de janeiro de 1999-outubro de 2015. Os autores que se sensibilizaram em escrever são de entidades federais igualmente divididos entre universidades e o Jardim Botânico do Rio de Janeiro que só atua com pósgraduação.

Quadro 4: Produtos de DC sob a forma de artigos no periódico Ciência Hoje de janeiro de 1999-outubro de 2015.

\begin{tabular}{|l|l|l|l|}
\hline \multicolumn{1}{|c|}{ Autores } & $\begin{array}{c}\text { Entidade do } \\
\text { Autor }\end{array}$ & \multicolumn{1}{c|}{ Título da matéria } & \multicolumn{1}{c|}{ Ano } \\
\hline Isabela Fraga & ICH & Algas promissoras & 2010 \\
\hline Andre Marques & ICH & Novos antivirais a vista & 2006 \\
\hline Eliane Soriano & UFRN & Filtros vivos para limpar a água & 2005 \\
\hline Fernanda Marques & ICH & Quem planta colhe & 2003 \\
\hline Gilberto Amado Filho & IPJBRJ & $\begin{array}{l}\text { As algas verdes, pardas e vermelhas são classificadas } \\
\text { hoje como no reino vegetal ou protista? }\end{array}$ & 2002 \\
\hline Mara Figueira & ICH & O mapa das algas & 2001 \\
\hline Marcia Figueiredo & IPJBRJ & Recife de Corais ou recifes de algas & 2000 \\
\hline Roberto B. de Carvalho & ICH & Algas assassinas & 1999 \\
\hline
\end{tabular}

Legenda: UFRN: Universidade Federal do Rio Grande do Norte; UFF: Universidade Federal Fluminense; IPJBRJ: Instituto de Pesquisas Jardim Botânico do Rio de Janeiro; UFRJ: Universidade Federal do Rio de Janeiro; ICH: Instituto Ciência Hoje.

O Quadro 5 evidencia uma baixa contribuição os quatro textos, sendo ainda um deles de ocorrência casual num texto de acidificação dos oceanos. O outro também não é exatamente sobre as algas e sim sobre uma especialidade dos cientistas para estudar as algas. De fato, os dois trabalhos foram formulados por cientistas de universidades (Creed/Reis e Hotta) é que tratariam das algas em si. Hotta trata do aspecto utilitário das algas, mas Creed/Reis não tratam essencialmente de algas e sim das "gramas marinhas" em 90\% de seu texto. Ou seja, o título do trabalho pode ter gerado confusão também quando ele foi indexado pela revista.

Quadro 5: Produtos de DC sob a forma de artigos no periódico Ciência Hoje das Crianças de 1999-outubro de 2015.

\begin{tabular}{|l|l|l|l|}
\hline Autores & Entidade do Autor & Título da matéria & Ano \\
\hline Carlos Takeshi Hotta & IB/USP & Prato do Dia: algas! & 2003 \\
\hline Carolina Benjamin & ICH & Quando crescer vou ser.... ficólogo. & 2004 \\
\hline Cátia Fernandes Barbosa & IQ/UFF & $\begin{array}{l}\text { Aviso aos navegantes. } \\
\text { (cita indiretamente alga no texto sobre } \\
\text { acidificação dos oceanos) }\end{array}$ & 2007 \\
\hline $\begin{array}{l}\text { Joel Christopher Creed e } \\
\text { Renata Perpétuo Reis }\end{array}$ & $\begin{array}{l}\text { IBRAG/ UERJ e } \\
\text { IPJBRJ }\end{array}$ & Um jardim no fundo do mar. & 2009 \\
\hline
\end{tabular}

Legenda: ICH: Instituto Ciência Hoje; IB/USP: Instituto de Biociências da Universidade de São Paulo; IQ/UFF: Instituto de Química da Universidade Fluminense; IBRAG/UERJ: Instituto de Biologia Roberto Alcântara Gomes da Universidade do Estado do Rio de Janeiro; IPJBRJ: Instituto de Pesquisas do Jardim Botânico do Rio de Janeiro.

Verifica-se uma baixa contribuição de matérias dirigidas ao público infantil, pois mesmo das quatro apresentadas como sendo sobre algas, só uma trata do tema em si. O Quadro 5 mostra que $75 \%$ dos artigos de $\mathrm{CHC}$ foram de cientistas de universidades e entidades de pesquisa públicas. Ou seja, o oposto do que 
ocorreu com $\mathrm{CH}$. Poderia se pressupor desinteresse dos jornalistas científicos em traduzir textos científicos para o público infantil? Ou tiveram dificuldades de tradução ou de simplificação?

Vale comentar que a recuperação dos produtos escritos de DC diretamente nos periódicos nem sempre são definitivamente corretos, pois o artigo de Araujo et al. (2015) na CHC só foi obtido na pesquisa direta com a pesquisa com os ficólogos. O mesmo também ocorre quando buscado diretamente com o autor que muitas vezes não tem interesse em colaborar com a pesquisa e assim a recuperação, usando os dois métodos se consolida, aumentando sua eficácia. Ou seja, uma triangulação metodológica parece a abordagem mais indicada para se aumentar a eficácia de recuperação dos produtos de DC: a) pesquisa direta aos cientistas; b) levantamento aos veículos potenciais de comunicação dos produtos; c) inventário juntos aos relatórios de financiadores.

\section{DISCUSSÃO}

\section{Quanto aos Produtos Totais Obtidos Junto aos Cientistas}

Os quatro produtos de divulgação científica unidirecionais foram formulados, pressupondo desconhecimento total do público receptor. E como não foram feitos estudos de avaliação de eficácia de transferência de informação não se pode concluir nada em termos de divulgação científica. Destes estudos, apenas o mais atual é dirigido ao público pré-adolescente e infantil. É um trabalho inédito, pois jamais os ficólogos se preocuparam em se dirigir às crianças brasileiras através de um produto escrito, mesmo que com muitos desenhos e esquemas. A eficácia desse tipo de produto de divulgação científica por parte do público receptor também é uma demanda necessária. É interessante comentar que Rua et al. (2015) identificaram em seu estudo de percepção sobre o mar e seus constituintes que crianças que vivem na zona norte da cidade do Rio de Janeiro percebem as algas marinhas. As algas, segundo as crianças, ocupam o segundo lugar após os peixes dentre os componentes biológicos que podem ocorrer no mar. É possível, então supor que a divulgação científica por textos escritos possa não deve estar sendo tão efetiva quanto a contribuição de desenhos animados ou filmes da TV (RUA et al., 2015). Alguns autores já mencionaram que o periódico Ciência Hoje mesmo tendo como meta ser uma revista de divulgação científica, não passa de uma disseminadora científica (HERNANDES-CANADAS, 1987). Ou seja, não vem cumprindo seu papel de popularizar o conhecimento científico em outras áreas do saber, devendo ocorrer o mesmo com a ficologia.

A realização do produto de DC através de dois ciclos de debates mesmo que ainda bidirecional trouxe agregação de valor a sociedade, pois fora adequadamente traduzido (ZAMBONI, 2001). A avaliação produzida pela confrontação do pré/pós-testes e a avaliação final, feita pelos 30 participantes de mais de 20 escolas diferentes, evidenciou que os debates atingiram seus objetivos de divulgar o conhecimento científico. Com os dados e as informações científicas transformadas em saber contextualizado incentivou a sociedade local a exercer sua cidadania. Souberam beneficiar-se do conhecimento gerado pelos cientistas de variadas matizes e especialidades que atuaram/atuam em seu ambiente cotidiano. Alcançaram, como previram Araújo, Caluzi e Caldeira (2006), a sua Alfabetização Científica percebendo que o conhecimento científico é 
gerado por uma comunidade científica que se dispôs a ir conversar com os moradores. Como previsto por Perez et al. (2006) os cientistas prestaram contas de suas atividades ao público, em diálogo direto, esclarecendo suas dúvidas. Além de passarem a ter acesso aos dados e informações os moradores podem também angariar a simpatia dos cientistas para suas teses e lutas populares, e além de apoio para formulação de anteprojetos de políticas públicas. Com acesso facilitado aos cientistas, de dezenas de entidades públicas, a sociedade pode problematizar suas questões socioambientais e assim planejar novas estratégias para um ambiente mais saudável às suas famílias.

O produto de simulação permitiu que o cidadão pudesse perscrutar o cotidiano do cientista e desmistificar a percepção idealizada pela mídia de que o cientista vive num mundo de fantasia onde tudo lhe é concedido para que ele descubra tudo que é necessário. Mostrou ao cidadão que o cientista é mais um empregado público que está submetido às instabilidades governamentais tanto salariais como de infraestrutura. E que seus produtos nem sempre são de conhecimento público e sim múltiplos papéis burocráticos exigidos pelo estado (Latour et al., 1987).

\section{Quanto aos Produtos em CH e CHC}

Vale ressaltar que alguns dos produtos apontados pelos cientistas como sua produção em revistas de DC não foram recuperados quando foram buscados na fonte. Por exemplo, na revista $\mathrm{CHC}$, Araujo et al. (2015) não tiveram recuperado seu artigo "Florestas Submarinas" quando a pesquisa foi feita diretamente na revista. O mesmo ocorreu com Soriano et al. (2008) na revista CH com seu artigo "Biodiversidade em risco". Essa dificuldade de recuperação de matérias em sistemas de informação, usando palavras-chaves, pode incorrer em imprecisões (ARAUJO JÚNIOR et al., 2006).

\section{Avaliação Global}

O número total de 22 produtos de DC obtidos em ficologia tanto por pesquisa junto aos ficólogos quanto em pesquisa a Ciência Hoje e Ciência Hoje das Crianças no período de janeiro de 1999 a outubro de 2015 é incipiente. No entanto, apenas 16 deles foram formulados por ficólogos, sendo $27 \%$ produzidos por jornalistas científicos. Então 1,6\% de cientistas contribuem com produtos sobre algas em um universo de 1.000 ficólogos, sugerindo uma contribuição incipiente. A produção de DC apenas medida por artigos de ficólogos na revista $\mathrm{CH}$ foi de $0,004 \%$ e em $\mathrm{CHC}$ foi de $0,0056 \%$, respectivamente, sendo 709 o total pressuposto de matérias das duas revistas no período estudado. Esse número é considerado baixo, partindo do princípio que caberia a cada um dos 1.000 ficólogos fazer pelo mesmo um produto. Ou seja, a produção em DC tanto no seu conjunto se comparada ao total de cientistas como ao total de matérias na revista de DC consagrada no meio científico parece ínfima se comparada com Kidd (1988).

Cabe comentar que nem todos os produtos recuperados junto aos ficólogos foram os mesmos obtidos em contato com as fontes de informação dos produtos de DC. Algumas hipóteses podem ser elencadas para tentar explicar esse comportamento. Isso pode sugerir um certo acomodamento, desinteresse e relaxamento pelo desconhecimento do tema da DC pelos ficólogos. Ou quiçá considerar o 
público um não ator social necessário na construção da agenda de pesquisa em C \& T no país. Ou os cientistas precisam seguir o lema de publicar ou perecer e publicar sempre em periódicos com alto fator de impacto (LATOUR et al., 1987) o que existe nas revistas de DC. Para conseguir publicar neles precisam equiparar-se a equipes que países adiantados cientificamente e obter equipamentos que eles possuem. Para isso, precisam obter financiamentos de altas somas. Assim, precisam igualmente produzir cooperações internacionais e receber esses cientistas nos seus laboratórios e também estagiar no exterior. Assumem dezenas de atribuições, assim como aulas de graduação nas suas entidades como de pós-graduação. Não são estimulados na sua capacitação, desde a graduação, a se comunicar com o grande público, pois atualmente deixam essa função aos jornalistas científicos (PEDRINI, 1999). Então, talvez por isso o cientista não acumule mais essa atribuição. As revistas de DC do exterior são desconhecidas para a maioria do cientista brasileiro e escrever para um público leigo não parece ser tão fácil. Desta forma, parece que os ficólogos não têm tempo para assumir esse encargo extra ao mesmo tempo em que desconhecem o campo da DC.

O presente artigo evidenciou que das matérias produzidas em ficologia nas revistas de DC a maioria (62\%), foi feita por jornalistas da própria revista. Isso pode sugerir que a ficologia brasileira estivesse disseminando muitos assuntos relevantes sem que a comunidade científica estivesse encaminhando textos de $\mathrm{DC}$ à $\mathrm{CH} / \mathrm{CHC}$. Assim, essa pauta coube aos jornalistas da revista para produzirem os textos na ocasião. Porém, o aumento repentino de encaminhamento de matérias em ficologia ou outras especialidades científicas para a CH também pode criar um impedimento à sua publicação. Alicia Ivanissevich (comunicação pessoal) - editora executiva de $\mathrm{CH}$ - afirma que a revista precisa variar o seu escopo e não pode publicar seguidamente matérias com o mesmo conteúdo. Há necessidade de equilíbrio temático na pauta.

Dessa forma, a hipótese pode ser comprovada, pois os cientistas ambientais representados pelos ficólogos não desenvolvem produtos de divulgação científica quando comparados com o seu número de acadêmicos. $O$ ideal seria que se identificasse, pelo menos, 1.000 produtos e não apenas 16 em 15 anos. Porém, os resultados do presente estudo de caso não podem ser generalizados e o presente estudo deveria ser refeito em escala de tempo maior e em várias outras especialidades científicas. Talvez os resultados aqui relatados pudessem ser aumentados em outras especialidades e abrangendo outros periódicos de divulgação científica.

De fato, os cientistas assim se esforçaram, mesmo que em escala incipiente para cumprir as metas preconizadas por Moreira (2006) quando da criação do Departamento de Difusão e Popularização de Ciência e Tecnologia do Ministério de Ciência, Tecnologia e Inovação. Poderia se preconizar que cada cientista poderia associar aos seus produtos de disseminação outro de divulgação científica.

Cientistas ficólogos, como os de outras especialidades, aliados a jornalistas científicos podem se associar e variar seus instrumentos e produtos em divulgação científica. Associados podem qualificar melhor a sociedade para o debate tão necessário (MOURA, 2006) de que temas são importantes e urgentes para comporem a agenda em Ciência, Tecnologia e Inovação do Brasil. 


\section{CONCLUSÃO E RECOMENDAÇÕES}

A hipótese testada foi aprovada. Ou seja, os ficólogos não produzem a divulgação científica ao público leigo da sociedade brasileira. Cabem aos cientistas e jornalistas se associarem e qualificar a sociedade brasileira para definirem a agenda em Ciência, Tecnologia e Inovação do Brasil.

Serão listadas a seguir doze recomendações mínimas para adoção imediata.

1. Adotar o modelo de Projeto de Pesquisa Científica associado a um Projeto de Divulgação Científica, e, se possível, também a um de Educação Ambiental. O Quadro 6 apresenta os projetos coletivos contemplados com ajuda de órgãos fomentadores de pesquisa e divulgação científicas em vigor por duas equipes de docentes da UERJ. A reunião de cientistas em equipes multidisciplinares em uma só equipe aumenta as chances de receber ajuda financeira aos projetos individuais.

2. Promover um inventário do que existe de publicado sobre produtos de divulgação científica em algas no Brasil e no estrangeiro de nossas espécies, populações, comunidades e ambientes apropriados a ocorrências de algas.

3. Criar linhas de pesquisa nesse campo, buscando articulação para cooperações com cursos de pós-graduação em Comunicação e Jornalismo das universidades brasileiras e internacionais.

4. Associar a cada projeto de pesquisa sobre algas, um subprojeto sobre DC multidirecional e de EA, com apoio pedagógico dialógico-problematizador de base freireana, de modo a divulgar a comunidade onde se coletam/trabalham com as algas algumas atividades nesse sentido;

5. Incluir nos cursos de mestrado e doutorado uma linha sobre DC.

6. Criar e ministrar disciplinas de DC sobre algas nos cursos de licenciatura e bacharelado e doutorado em Ciências Biológicas e Oceanografia, exigindo a formulação de um produto multidirecional para aprovação.

7. Pleitear editais às fundações de amparo à pesquisa e CNPq para DC;

8. Solicitar aos comitês de avaliação das entidades de fomento que valorem os artigos de periódicos de DC de modo a que, pelo menos, um deles possa ser classificado como QUALIS A;

9. Promover cursos de capacitação em ficologia para jornalistas/divulgadores científicos.

10. Promover nas reuniões científicas da ficologia prêmios para desenvolvimento de novas técnicas de DC com algas; como uma linha do Prêmio Joly da Sociedade Brasileira de Ficologia e do Prêmio Yocie Yoneshigue-Valentin da RedeAlgas;

11. Capacitar cientistas interessados em se comunicar diretamente com a sociedade a como se preparar para as visitas cotidianas aos laboratórios ou para formular projetos/programas de simulações.

12. Buscar formular cooperações internacionais com o fim de capacitar jovens doutores a se capacitar em DC.

Quadro 6: Nomes dos projetos coletivos aprovados por entidades de fomento à pesquisa e respectivas entidades financiadoras; o de Educação Ambiental é apenas uma sugestão.

\begin{tabular}{|l|l|}
\hline \multicolumn{1}{|c|}{ Tipo } & \multicolumn{1}{c|}{ Nome dos Projetos Coletivos de Auxílio } \\
\hline $\begin{array}{l}\text { Pesquisa } \\
\text { Científica }\end{array}$ & $\begin{array}{l}\text { Adequação do Centro de Estudos Ambientais e Desenvolvimento Sustentável (Ceads)/UERJ para estudos em } \\
\text { Biodiversidade Marinha (FAPERJ-Edital de Apoio a Entidades Estaduais) }\end{array}$ \\
\hline $\begin{array}{l}\text { Divulgação } \\
\text { Científica }\end{array}$ & $\begin{array}{l}\text { Conhecendo e Divulgando a Diversidade Ambiental da Baía da Ilha Grande: base para o desenvolvimento social } \\
\text { sustentável (CNPq-Difusão e Popularização da Ciência) }\end{array}$ \\
\hline $\begin{array}{l}\text { Educação } \\
\text { Ambiental }\end{array}$ & $\begin{array}{l}\text { Educação Ambiental Emancipatória pelo Ecoturismo Marinho de Base Comunitária no Parque Estadual da Ilha } \\
\text { Grande, Angra dos Reis, Rio de Janeiro. }\end{array}$ \\
\hline
\end{tabular}




\section{AGRADECIMENTOS}

A doação de publicações da Biblioteca da Comissão Nacional de Energia Nuclear que me permitiram dados das fundações de amparo a pesquisa estaduais. À Comissão Organizadora (Ricardo Coutinho e Yocie Yoneshigue Valentin, em particular) da V Reunião da RedeAlgas que indiretamente me incentivou a formular esse trabalho.

Ao Paulo Horta e Jose Bonomi Barufi-diretores da Sociedade Brasileira de Ficologia- pelo apoio na coleta de dados aos seus associados. As editoras da revista Ciência Hoje e Ciencia Hoje das Crianças, respectivamente, Alicia Ivanissevich e Bianca Encarnação pela obtenção dos dados nos respectivos periódicos. A Jalton Gil Torres Pinho pela revisão do texto.

À Farmácia Homeopática PhD pela doação de amostras. Ao Prof. Luis Felipe Skinner da FFP/UERJ pela liderança da equipe de Biologia Marinha da UERJ e que conseguiu os dois auxílios.

Ao CNPq pela chamada N 90/2013 MCTI/CNPq/SECIS, Difusão e Popularização da Ciência que nos incentiva a seguir no modelo de associar pesquisa científica com divulgação em ciência.

\section{REFERÊNCIAS}

ABRAMUNDO, I.; EDUCATIVA, AÇÃO; MONTENEGRO, P. I.. Indicador de Letramento Científico. Relatório técnico da edição 2014, São Paulo: 2014, 27 p.

ARAUJO, E. S. N. N.; CALUZI, J. J.; CALDEIRA, A. M. A. Divulgação e Cultura Científica. In: ARAUJO, E. S. N. N.; CALUZI, J. J.; CALDEIRA, A. M. A.. Divulgação Científica e Ensino de Ciências: estudos e experiências. São Paulo: Escrituras, 2006. p.15-34.

ARAUJO, J. P. G.; SZÉCHY, M. T. M.. Florestas submersas. Ciência Hoje das Crianças, Rio de Janeiro, n.270, p.6-9, ago, 2015.

ARAUJO JUNIOR, R. H.; TARAPANOF, K.. Precisão no processo de busca e recuperação da informação: uso da mineração de textos. Ciência da Informação, Brasília, v.35, n.3, p.236-247, 2006.

BARRETO, A. A.. A Questão da Informação. Perspectiva, São Paulo, v.8, n.4, p.3-8, 1994.

BURKETT, W.. Jornalismo Científico: como escrever sobre ciência, medicina e alta tecnologia para os meios de comunicação. Rio de Janeiro: Forense Universitária, 1990.

BUENO, W. C.. Jornalismo científico: conceitos e funções. Ciência e Cultura, n.37, v.9, p.1420-1428, 1985.

CARSON, R.. Beira-Mar. São Paulo: Gaia, 2010.

CASTELAR, B.; REIS, R. P.; MOURA, A. L.; KIRK, R.. Invasive potential of Kappaphycus alvarezii off the south coast of Rio de Janeiro state, Brazil: a contribution to environmentally secure cultivation in the tropics. Botanica Marina, Berlin, v.52, n.4, p.283-289, 2009.

COPERTINO, M. S.. Add coastal vegetation to the climate critical list. Nature, v.473, p.255, 2011.
MCTI. Divulgação científica é debatida na 67ạ Reunião da SBPC. Notícia. Brasília: MCTI, 2015.

FAUSTO NETO, A.. Midiatização da Ciência; cenários, desafios, possibilidades. Campina Grande: EdUEPb, 2012.

FAHY, D.; LEWENSTEIN, B. V.. Scientists in popular culture. In: BUCHIM, M.; TRENCH, B.. Handbook of Public Communication of Science and Technology. 2 ed. London: Routledge, 2014.

FIGUEIREDO, M. A. O.. Recifes de corais ou recifes de algas. Ciência Hoje, v.28, n.166, p.74-76, 2000.

FAPESP. Fundação de Amparo à Pesquisa do Estado de São Paulo. Relatório de Atividades 2014. São Paulo: FAPESP, 2015.

FUNDAÇÃO CARLOS CHAGAS FILHO DE AMPARO À PESQUISA DO ESTADO DO RIO DE JANEIRO. Memórias da FAPERJ: A trajetória da agência de fomento à Ciência, Tecnologia e Inovação do Estado do Rio de Janeiro (1980-2013). Rio de Janeiro: FAPERJ, 2013.

GHILARDI-LOPES, N. P.; HADEL, V. F.; BERCHEZ, F.. Guia para Educação Ambiental em Costões Rochosos. Porto Alegre: Artmed, 2012.

GUSTON, G.; KENINSTON, K.. The Fragile Contract: Introduction. In: GUSTON, G.; KENINSTON, K.. The Fragile Contract. Massachusets. Boston: MIT Press, 1994. p.7-25

HORTA, P. A.; LAUDARES-SILVA, R.; RORIG, L.; DONANGELO, L.; BURGOS, D. C.. Sistemas de Classificação de Macroalgas; bases para um estudo taxonômico. In: PEDRINI, A. G.. Macroalgas; Uma Introdução a Taxonomia. Rio de Janeiro: Technical Books, 2010. p.29-51 
HERNANDEZ-CANADAS, P. L.. Os periódicos Ciência Hoje e Ciência e Cultura e a divulgação em Ciência no Brasil. Dissertação (Mestrado em Ciência da Informação) Universidade Federal do Rio de Janeiro, 1987.

IANINI, A. M. N.; FARES, D. C.; BIZERRA, A; MARANDINO, M. Pesquisa em Divulgação Científica: Um Levantamento de Referenciais Teóricos Nacionais. In: ENCONTRO NACIONAL DE PESQUISA EM EDUCAÇÃO EM CIÊNCIA, 6. Anais. Florianópolis: ENPEC, 2007.

IVANISSEVICH, A.. A missão de divulgar ciência no Brasil. Ciência e Cultura, Rio de Janeiro, v.61, n.1, p.4-5, 2009.

KIDD, S. S.. The popularization of science: some basic measurements. Scientometrics, v.14, n.1-2, p.127-142, 1988.

KNOR-CETINA, K.. The Manufacture of Knowledge; an essay on the Construtivism. Oxford: Pergamon Press, 1981.

LAPLANE, M.. Percepção Pública da C \& T no Brasil 2015; Ciência e tecnologia no olhar dos brasileiros: sumário executivo. Brasília: Centro de Gestão e Estudo Estratégicos, 2015.

LATOUR, B.; WOOLGAR, S.. A vida do laboratório: a produção dos fatos científicos. Rio de Janeiro: Relume Dumará, 1997.

MALAVOY, S.. Guia prático de Divulgação Científica. Rio de Janeiro: Casa de Oswaldo Cruz, 2005.

MASSARANI, L., MOREIRA, I. C.. A retórica e a ciências; dos artigos originais à divulgação científica. Multiciência, v.4, p.1-18, 2005

MASSARANI, L., MOREIRA, I. C.; BRITO, F.. Ciência e Público: caminhos da divulgação científica no Brasil. Rio de Janeiro: EdUFRJ, 2002.

MCT. Ministério de Ciência e Tecnologia. $\mathbf{O}$ que o brasileiro pensa da Ciência e Tecnologia? : a imagem da ciência e da tecnologia junto à população urbana brasileira. 2 ed. Rio de Janeiro: MAST, 1988.

MOREIRA, I. C.. A inclusão social e a popularização da ciência e tecnologia no Brasil. Inclusão Social, Brasília, v.1, n.2, p.1116, 2006.

MÜLLER-HILL, B.. Ciência Assassina; como cientistas alemães contribuíram para a eliminação de judeus, ciganos e outras minorias durante o nazismo. Rio de Janeiro: Xenon, 1993.

NASSAR, M. C.. Algas Marinhas do Brasil. Rio de Janeiro: Technical Books, 2012.

NELSON, P.. Dez dicas práticas para reportagens sobre o meio ambiente. Brasília: WWF, 1994.

OIGMAN-PSZCZOL, S. S; OLIVEIRA, A. E. S.; CREED, J. C. Perceptions of coral in a coastal tourist town in Brazil. Coral Reefs, v.26, p.667-670, 2007.

OLIVEIRA FILHO, E.. Introdução a Biologia Vegetal. 2 ed. São Paulo: EdUSP, 2003.
OLIVEIRA, F.. Jornalismo Científico. 2 ed. São Paulo: Contexto, 2005.

PEDRINI, A. G.. Ciência e Sociedade; a Divulgação Científica por meio de Ciclos de Debates In: CONGRESSO LATINOAMERICANO DA REDE DE POPULARIZAÇÃO DA CIÊNCIA E TECNOLOGIA DA AMÉRICA LATINA E CARIBE, 6. Anais. Rio de Janeiro, 1999.

PEDRINI, A. G.. O Cientista e os Métodos de Avaliação de seu Desempenho: estudo de sua adequação no contexto brasileiro. Tese (Doutorado em Ciência da Informação) Universidade Federal do Rio de Janeiro, Rio de Janeiro, 2000.

PEDRINI, A. G.. Educação Ambiental Marinha e Costeira no Brasil. Rio de Janeiro: EdUERJ, 2010a.

PEDRINI, A. G.. Macroalgas Marinhas: importância geral. In: PEDRINI, A. G.. Macroalgas: uma introdução à taxonomia. Rio de Janeiro: Technical Books, 2010b, p.2-11

PEDRINI, A. G.. Macroalgas: uma introdução à taxonomia. Rio de Janeiro: Technical Books, 2010c.

PEDRINI, A. G.. Macroalgas (Chlorophyta) e gramas (Magnoliophyta) marinhas do Brasil. Rio de Janeiro: Technical Books, 2011.

PEDRINI, A. G.. Macroalgas (Ocrófitas Multicelulares) Marinhas do Brasil. Rio de Janeiro: Technical Books, 2013.

PEDRINI, A. G.; CARNEIRO, L. A.. Ecologia, manejo e política ambiental. In: CICLO DE CONFERÊNCIAS E DEBATES SOBRE AS LAGUNAS DA BAIXADA DE JACAREPAGUÁ. Anais. Rio de Janeiro: UERJ, 1984.

PEDRINI, A. G.; CARNEIRO, L. A.. Ecologia, manejo e política ambiental. In: CICLO DE CONFERÊNCIAS E DEBATES SOBRE AS LAGUNAS DA BAIXADA DE JACAREPAGUÁ, 2. Anais. Rio de Janeiro: UERJ, 1991.

PEDRINI, A. G.; DE-PAULA, J. C.; CASSANO, V.. Ciência e Sociedade: a Divulgação Científica por meio de Oficinas de Simulação. In: CONGRESSO LATINO-AMERICANO DA REDE DE POPULARIZAÇÃO DA CIÊNCIA E TECNOLOGIA DA AMÉRICA LATINA E CARIBE, 6. Anais. Rio de Janeiro, 1999.

PEREZ, J. R. B.; CALUZI, J. J. A divulgação científica e o ensino de física moderna. In: ARAUJO, E. S. N. N.; CALUZI, J. J.; CALDEIRA, A. M. A.. Divulgação Científica e Ensino de Ciências: estudos e experiências. São Paulo: Escrituras, 2006. p.57-93

REIS, J.. Divulgação da ciência. Ciência e Cultura, v.6, n.2, p.57-60, 1954

ROSA, C. N.. Os animais de nossas praias. São Paulo: Edart, 1973.

RUA, M. B.; PEDRINI, A. G.; BERNARDES, L.; MARIANO, D.; FONSECA, L. B.; NUNES, R. M.; BROTTO, D. S.. Percepção do ambiente marinho por crianças no Rio de Janeiro, Brasil. Revista Biociências, v.21, n.1, p.27-44, 2015. 
SORIANO, E. M.; CARNEIRO, M. A. A.; SORIANO, J.. Manual de identificação das macroalgas marinhas do litoral do Rio Grande do Norte. Natal: EDUFRN, 2009.

SORIANO, E. M.; SILVA, I. B.; MARTINS, E. O. V.; AMARAL, F. D. O.. Biodiversidade em risco. Ciência Hoje, Rio de Janeiro, v.42, n.247, p.68-70, 2008.

THUILLIER, P.. O Contexto Cultural da Ciência. Ciência Hoje, v.9, n.50, p.18-23, 1989.

VASCONCELOS, F. A. L. D.; AMARAL, F. D.; STEINER, A. Q.. Uma visão da classe estudantil sobre ambientes recifais na Região Metropolitana do Recife, Estado de Pernambuco, Brasil. Arq. Ciên. Mar, Fortaleza, v.41, n.1, p.104-112, 2008.
VIEIRA, R.; PEREIRA, R.; ARENAS, F.; ARAUJO, R.; PINTO, I. S. Guia de campo; espécies intertidais características da costa norte de Portugal: praias rochosas. Porto: Programa Escolar de Monitorização da Biodiversidade Intertidal e Divulgação Científica, 2013.

ZAMBONI, L. M. S.. Cientistas, jornalistas e a divulgação científica: subjetividade e heterogeneidade no discurso de divulgação científica. Campinas: Autores Associados, 2001.

ZIMAN, J. M.. Conhecimento Público. Belo Horizonte: São Paulo: EdUSP, 1979. 